ISSN 2073-4352

www.mdpi.com/journal/crystals

Article

\title{
Betaine Chloride-Betaine Tetrachloridoferrate(III)_An Ionic Liquid Related Crystal Structure Governed by the Pearson Concept
}

\section{Tobias Bäcker and Anja-Verena Mudring *}

Fakultät für Chemie und Biochemie, Ruhr-Universität, Universitätsstraße 150, D-44780 Bochum, Germany; E-Mail: tobias.baecker-2@rub.de

* Author to whom correspondence should be addressed; E-Mail: anja.mudring@ @rub.de;

Tel.: +49-234-32-29028; Fax: +49-234-32-14951.

Received: 16 January 2012; in revised form: 1 February 2012 / Accepted: 3 February 2012 /

Published: 12 March 2012

\begin{abstract}
The first betaine chloride tetrachloroidoferrate(III) double salt, $(\mathrm{Hbet})_{2} \mathrm{Cl}\left[\mathrm{FeCl}_{4}\right]=$ (Hbet)Cl$\cdot(\mathrm{Hbet})\left[\mathrm{FeCl}_{4}\right]$, was obtained from a solution of betaine hydrochloride (HbetCl) and $\mathrm{FeCl}_{3} \cdot 6 \quad \mathrm{H}_{2} \mathrm{O}$ in water. The crystal structure (orthorhombic, Pbcm, $a=6.2717(13), b=12.841(3), c=25.693(5) \AA, Z=4$ ) is characterized by layers of tetrachloridoferrate(III) anions separated by chloride-bridged, H-bond mediated cationic (Hbet) dimers. The hydrogen bonding network in the crystal structure follows the Pearson HSAB (hard acid-soft base) concept: According to the Pearson concept, the chloride anions show high affinity to the carboxyl group (hard acid and base), and the tetrachloroidoferrate(III) anion preferentially interacts with the activated methyl donors (soft acid and base). These interactions between the $\mathrm{COOH}$ group, as hard H-bond donor, and chloride as hard acceptor besides those between the soft, activated methyl groups and the soft tetrachloridoferrate(III) anions are the major structure-directing forces in the crystal structure of (Hbet) ${ }_{2} \mathrm{Cl}\left[\mathrm{FeCl}_{4}\right]$.
\end{abstract}

Keywords: betaine; chloride; tetrachloridoferrate; double salt 


\section{Introduction}

Betaine (trimethyl-carboxymethylammonium zwitter salt, bet) and its protonated form (Hbet), also known as $\mathrm{N}$-trimethylglycine, is a naturally occurring metabolite [1]. Betaine and its esters are known to be biologically and pharmaceutically active substances. Betaine and its derivatives are known to have antimalarial activity [2] and can affect the autonomic nervous system and blood pressure [3]. Betaine esters were investigated for arteriosclerosis treatment [4]. In the context of ionic liquids, betainium has been used as a task-specific ionic liquid cation for dissolving metal oxides [5]. Historically, ionic liquids, i.e., salts that are molten below $100{ }^{\circ} \mathrm{C}$ and are often liquid already at room temperature, have received substantial interest first as electrolytes and then as potentially environmentally benign replacements of volatile organic solvents in synthesis [6]. Nowadays it is realized that the full potential of ionic liquids probably lies in more specialized applications due to their modular character which allows for designed properties. Recently, a new class of ionic liquids has been found: pharmaceutically active ionic liquids [7,8]. By involving pharmaceutically active ingredients into an ionic liquid their bioavailability can be enhanced [7]. However, this requires their transformation into a room temperature ionic liquid. To this end, the ability to form hydrogen bonds has been found to be important [9].

The protonated form of the betaine zwitterion, (Hbet) ${ }^{+}$, contains hydrogen bond donors with different donor strengths. The carboxylic group acts as a strong donor, whilst the methyl groups, albeit activated by the neighboring $\mathrm{N}$ atom, may act as nonclassical, weak donors [10]. Thus, the investigation of pharmaceutically active cations with anions of different hydrogen bonding acceptor qualities is important. (Hbet) $)_{2} \mathrm{Cl}\left[\mathrm{FeCl}_{4}\right]$, contains two types of anions, chloride and tetrachlorido-ferrate(III). The chloride anion is, according to the Pearson concept [11], a hard base with a high hydrogen bonding affinity. The tetrachloridoferrate(III) anion has a much lower charge/radius ratio and is a much weaker base according to the Pearson concept.

\section{Results and Discussion}

( $\mathrm{Hbet})_{2} \mathrm{Cl}\left[\mathrm{FeCl}_{4}\right]$ is crystallized from an aqueous solution of betaine hydrochloride (Hbet) $\mathrm{Cl}$ and iron(III) chloride hexahydrate upon isothermal solvent evaporation.

Figure 1. Asymmetric unit of the crystal structure of (Hbet) ${ }_{2} \mathrm{Cl}\left[\mathrm{FeCl}_{4}\right]$ with the atom numbering scheme.
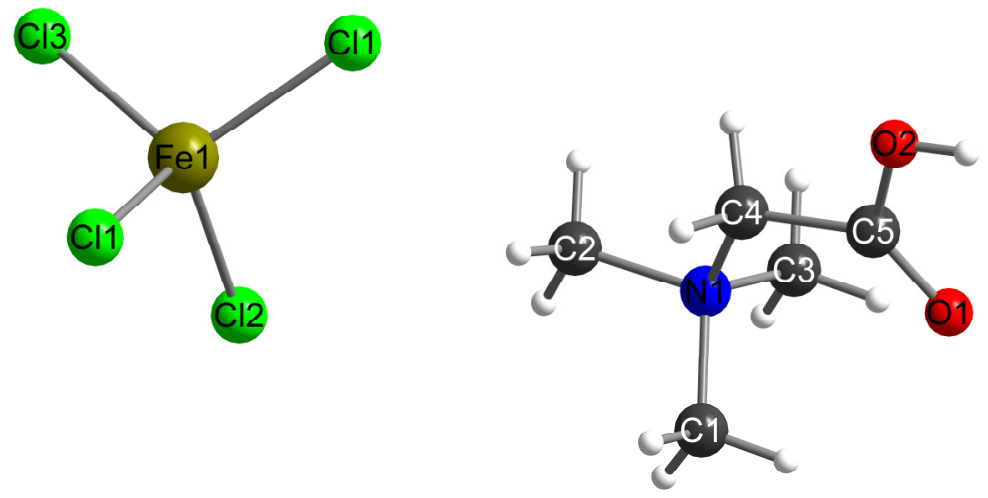
Single crystal X-ray structure analysis reveals that the asymmetric unit contains one (Hbet) ${ }^{+}$cation and one crystallographically independent unit of each anion, $\mathrm{Cl}^{-}$and $\left[\mathrm{FeCl}_{4}\right]^{-}$(see Figure 1 , for details on data collection and structure solution see Table 1).

Table 1. Crystallographic information about the structure solution of (Hbet) ${ }_{2} \mathrm{Cl}\left[\mathrm{FeCl}_{4}\right]$.

\begin{tabular}{cc}
\hline formula & $\mathrm{C}_{10} \mathrm{H}_{24} \mathrm{~N}_{2} \mathrm{O}_{2} \mathrm{FeCl}_{5}$ \\
molar mass & 469.41 \\
crystal system & orthorhombic \\
space group & $P b c m(\mathrm{No} .57)$ \\
$a(\AA)$ & $6.2717(13)$ \\
$b(\AA)$ & $12.841(3)$ \\
$c(\AA)$ & $25.693(5)$ \\
$\alpha=\beta=\gamma$ & $90^{\circ}$ \\
volume $\left(\AA \AA^{3}\right)$ & $2069.2(8)$ \\
$\rho$ & 1.507 \\
$Z$ & 4 \\
$T(\mathrm{~K})$ & 170 \\
$\mathrm{~F}(000)$ & 964 \\
$\mu\left(\mathrm{mm}{ }^{-1}\right)$ & 1.388 \\
reflections & 11322 \\
unique & 1680 \\
$R_{\text {int }}$ & 0.1013 \\
$R_{1}$ & 0.0393 \\
w $R_{2}$ & 0.0752 \\
Goof & 0.80 \\
\hline
\end{tabular}

The tetrachloridoferrate(III) anion exhibits a distorted tetrahedral structure with an average $\mathrm{Fe}-\mathrm{Cl}$ distance of 2.192(2) $\AA$ and an average Cl-Fe-Cl angle of $109.47(7)^{\circ}$ (for details see Table 2), values which are typical for that kind of anion [12-16].

C-C and C-N distances within the cation (Table 3) also well match the typical values found for salts with the (Hbet) ${ }^{+}$cation, see for example in betainium bis(trifluoromethanesulfonyl)amide [15], bis(betainium)nitrate [17], or betainium hydrochloride [18].

Table 2. Distances and angles in the tetrachloridoferrate(III) anion in (Hbet) ${ }_{2} \mathrm{Cl}\left[\mathrm{FeCl}_{4}\right]$.

\begin{tabular}{cl}
\hline $\mathrm{Fe} 1-\mathrm{Cl} 1(2 \mathrm{x})$ & $2.187(1) \AA$ \\
$\mathrm{Fe} 1-\mathrm{Cl} 2$ & $2.186(2) \AA$ \\
$\mathrm{Fe} 1-\mathrm{Cl} 3$ & $2.207(2) \AA$ \\
$\mathrm{Cl} 1-\mathrm{Fe} 1-\mathrm{Cl} 1$ & $112.85(6)^{\circ}$ \\
$\mathrm{Cl} 1-\mathrm{Fe} 1-\mathrm{Cl} 2(2 \mathrm{x})$ & $108.36(7)^{\circ}$ \\
$\mathrm{Cl} 1-\mathrm{Fe} 1-\mathrm{Cl} 3(2 \mathrm{x})$ & $108.90(7)^{\circ}$ \\
$\mathrm{Cl} 2-\mathrm{Fe} 1-\mathrm{Cl} 3$ & $109.43(8)^{\circ}$ \\
\hline
\end{tabular}


Table 3. Distances in the betainium cation in (Hbet $)_{2} \mathrm{Cl}\left[\mathrm{FeCl}_{4}\right]$.

\begin{tabular}{ll}
\hline $\mathrm{C} 1-\mathrm{N} 1$ & $1.508(7) \AA$ \\
$\mathrm{C} 2-\mathrm{N} 1$ & $1.500(6) \AA$ \\
$\mathrm{C} 3-\mathrm{N} 1$ & $1.499(6) \AA$ \\
$\mathrm{N} 1-\mathrm{C} 4$ & $1.497(6) \AA$ \\
$\mathrm{C} 4-\mathrm{C} 5$ & $1.493(7) \AA$ \\
\hline
\end{tabular}

The four substituents of the central $\mathrm{N}$ atom on the (Hbet) ${ }^{+}$cation form a distorted tetrahedron. The angles between the carbon atoms of two neighboring methyl groups and the central $\mathrm{N}$ atom are smaller $\left.\left(<\mathrm{C} 2-\mathrm{N} 1-\mathrm{C} 3=108.1(4)^{\circ},<\mathrm{C} 2-\mathrm{N} 1-\mathrm{C} 1=109.4(4)^{\circ},<\mathrm{C} 1-\mathrm{N} 1-\mathrm{C} 3=109.6(4)^{\circ} \text {, average 108.9(4) }\right)^{\circ}\right)$ than the angles formed by one methyl group, the $\mathrm{N}$ atom and the carboxymethyl group, $\left(<\mathrm{C} 1-\mathrm{N} 1-\mathrm{C} 4=111.3(4)^{\circ},<\mathrm{C} 3-\mathrm{N} 1-\mathrm{C} 4=112.1(3)^{\circ},<\mathrm{C} 2-\mathrm{N} 1-\mathrm{C} 4=106.6(4)^{\circ}\right.$, average $\left.=110.0(4)^{\circ}\right)$. The C2-N1-C4 angle, 106.6(4) ${ }^{\circ}$, is compressed by the $\mathrm{C}=\mathrm{O}$ group being close to the $\mathrm{C} 1$ and $\mathrm{C} 3$ methyl groups. As expected, the protonated oxygen atom exhibits a larger $\mathrm{C}-\mathrm{O}$ interatomic distance than the non-protonated one, $\mathrm{d}(\mathrm{C} 5-\mathrm{O} 2)=1.315(6) \AA$ vs. $\mathrm{d}(\mathrm{C} 5-\mathrm{O} 1)=1.220(6) \AA$.

Hydrogen bonding seems to be the crucial factor which determines how the ionic constituents of (Hbet) ${ }_{2} \mathrm{Cl}\left[\mathrm{FeCl}_{4}\right]$ pack (Figure 2, Table 4)). On the one hand, the chloride ion, a hard base according to Pearson, interacts with the carboxylic group of the $(\mathrm{Hbet})^{+}$cation, a hard acid, $\mathrm{d}(\mathrm{O}-\mathrm{Cl})=3.000(4) \AA$, $\mathrm{d}(\mathrm{H}-\mathrm{Cl})=2.6188(5) \AA$. The chloride anion is further involved in a second but weaker hydrogen bond with the $\mathrm{CH}_{2}$ group of (Hbet $)^{+}, \mathrm{d}(\mathrm{C}-\mathrm{Cl})=3.535(5) \AA$ and $\mathrm{d}(\mathrm{H}-\mathrm{Cl})=2.1909(5) \AA$. On the other hand, the large tetrachloridoferrate(III) anion, a soft base, acts as hydrogen bond acceptor for the activated methyl groups of the (Hbet) ${ }^{+}$cation [10], which acts as a soft acid. This interaction is represented by hydrogen bonds between $\mathrm{C} 2$ and $\mathrm{Cl1}, \mathrm{d}(\mathrm{C}-\mathrm{Cl})=3.585(6) \AA$ and 3.650(6) $\AA, \mathrm{d}(\mathrm{H}-\mathrm{Cl})=2.949(1) \AA$ and 2.692(1) $\AA$, respectively). Typically, the strength of the hydrogen bonds can be directly correlated to the donor-acceptor distance [19]. It is obvious that the hydrogen bond between hard donor and acceptor with a distance of $3 \AA$ is significantly stronger than the hydrogen bonds between soft donors and acceptors with a distance larger than $3.5 \AA$.

Figure 2. Hydrogen bonding in (Hbet $)_{2} \mathrm{Cl}\left[\mathrm{FeCl}_{4}\right]$.

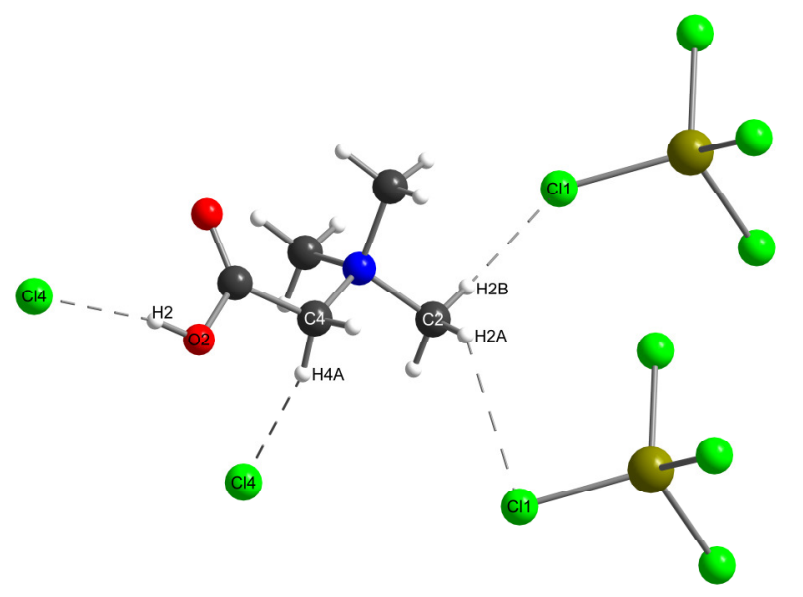


Table 4. Hydrogen bonding in (Hbet) $)_{2} \mathrm{Cl}\left[\mathrm{FeCl}_{4}\right]$.

\begin{tabular}{cc|cc}
\hline \multicolumn{2}{c|}{ d(donor-acceptor) } & \multicolumn{2}{c}{$\mathrm{d}(\mathrm{H}$-acceptor) } \\
\hline $\mathrm{C} 2-\mathrm{Cl} 1$ & $3.585(6) \AA$ & $\mathrm{H} 2 \mathrm{~A}-\mathrm{Cl} 1$ & $2.949(1) \AA$ \\
$\mathrm{C} 2-\mathrm{Cl} 1$ & $3.650(6) \AA$ & $\mathrm{H} 2 \mathrm{~B}-\mathrm{Cl} 1$ & $2.692(1) \AA$ \\
$\mathrm{C} 4-\mathrm{Cl} 4$ & $3.535(5) \AA$ & $\mathrm{H} 4 \mathrm{~A}-\mathrm{Cl} 4$ & $2.1909(5) \AA$ \\
$\mathrm{O} 2-\mathrm{Cl} 4$ & $3.000(4) \AA$ & $\mathrm{H} 2-\mathrm{Cl} 4$ & $2.6188(5) \AA$ \\
\hline
\end{tabular}

The strong hydrogen bonds allow the formation of chloride-bridged cationic dimers (Figure 3). The cationic dimers are connected by weaker $\mathrm{CH}_{2} \cdots \mathrm{Cl}^{-}$hydrogen bonds to layers. These chloride-cation layers are separated by layers of tetrachloridoferrate(III) anions showing weaker hydrogen bonding with the (Hbet) ${ }^{+}$cation (Figure 4). The anions in the tetrachloridoferrate(III) layers are arranged in rows parallel to the crystallographic $a$ axis and show alternating orientations. The orientation of the anions also alternates from one layer to the next.

Figure 3. Hydrogen bond mediated, chloride bridged cationic dimer.

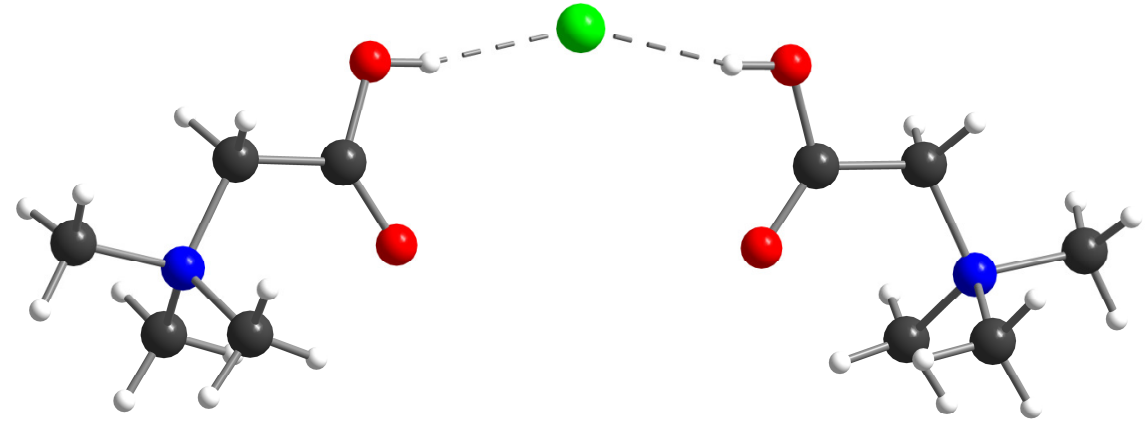

Figure 4. Layers packed in the crystal structure of (Hbet $)_{2} \mathrm{Cl}\left[\mathrm{FeCl}_{4}\right]$ (view down the $a$ axis).

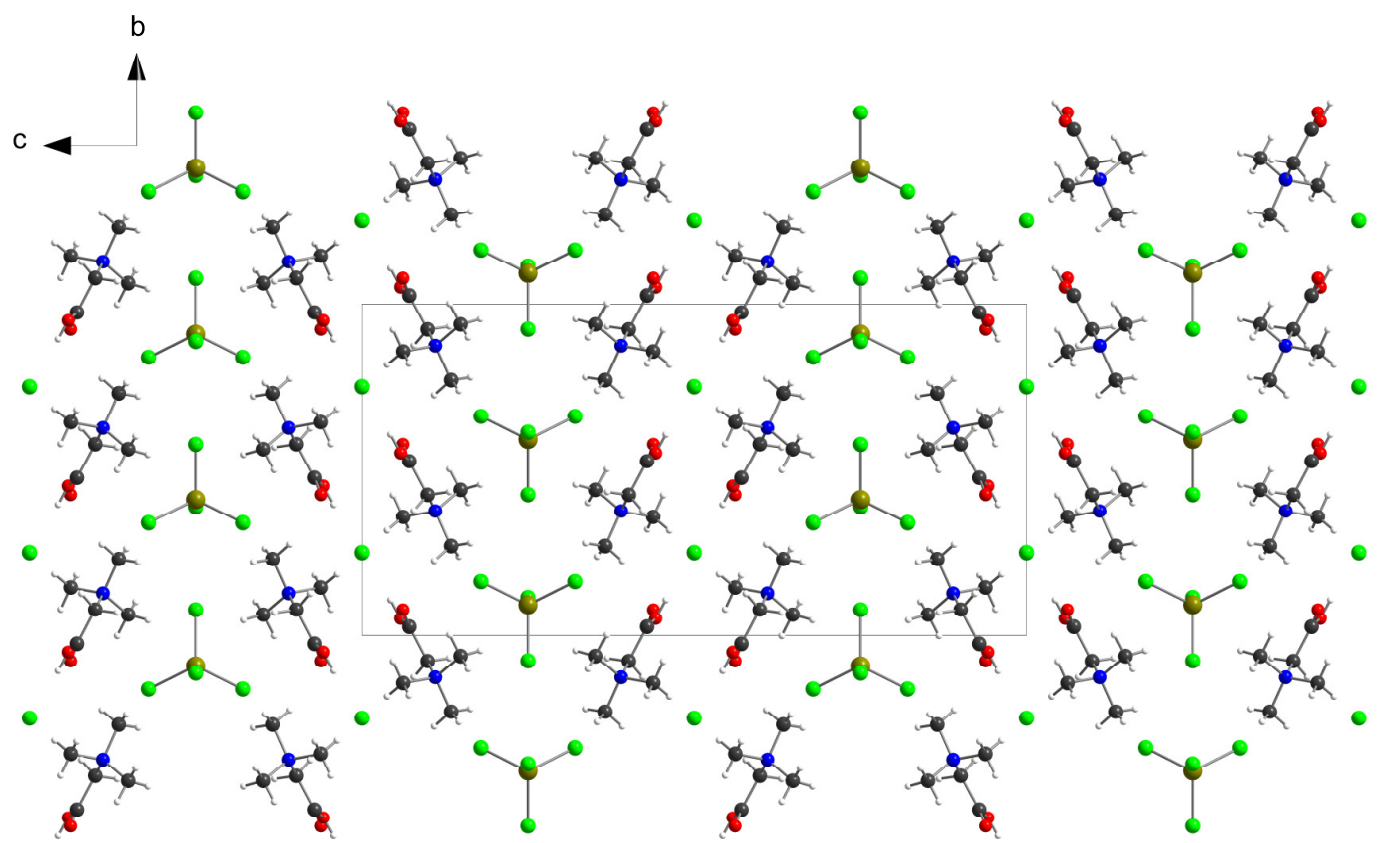




\section{Experimental Section}

Synthesis. $0.200 \mathrm{~g}(1.3 \mathrm{mmol})$ betainium hydrochloride (Acros, 99\%) were mixed with $0.352 \mathrm{~g}$ (1.3 mmol) $\mathrm{FeCl}_{3} \cdot 6 \mathrm{H}_{2} \mathrm{O}$ (ABCR, 99\%); the mixture was dissolved in ca. $15 \mathrm{~mL}$ water. Isothermal evaporation yielded small, plate-shaped, red-brown crystals together with some non-single crystalline, brown material.

$X$-ray structure analysis. A few crystals of the title compound were mounted on a glass fiber and checked by Laue photographs for their quality. The best specimen was used to collect a complete intensity data set with the aid of a single-crystal X-ray diffractometer (Stoe IPDS I, graphitemonochromated $\mathrm{MoK}_{\alpha}$ radiation, $\lambda=0.70173 \AA$ A). Data reduction with the program X-Red [20] included corrections for background, Lorentz and polarization effects. A numerical absorption correction with the programs X-Red/X-Shape [21] was carried out after optimization of the crystal morphology. The structure was solved by direct methods with the program SHELXS-97 [22]. The atoms were refined anisotropically against $F^{2}$ by a full-matrix least-square procedure using the program SHEXL-97. Hydrogen atoms were constrained to ride on their respective parent atom. Structure factors were taken from International Tables for Crystallography [23]. For crystal structure drawings, the program Diamond was used [24].

Crystallographic data (excluding structure factors) for the structure reported in this paper have been deposited with the Cambridge Crystallographic Data Centre. Copies of the data can be obtained free of charge on application to CCDC, 12 Union Road, Cambridge CB2 1EZ, UK [Fax: int. code +44(1223)336-033; E-Mail: deposit@ccdc.cam.ac.uk].

\section{Conclusions}

With the crystal structure of (Hbet) $)_{2} \mathrm{Cl}\left[\mathrm{FeCl}_{4}\right]$ we have shown that the Pearson concept is a powerful guide in crystal engineering. The interaction between strong hydrogen bond donors and acceptors leads to formation of layers with methyl groups capping the layers. These methyl groups act, due to their activation by the electron withdrawing nitrogen atoms, as soft hydrogen bond donors and interact with the tetrachloridoferrate(III) layer. This is a figurative example for a Pearson crystal.

\section{Acknowledgements}

AVM thanks the DFG for generous support within the priority program "Ionic Liquids" and the Fonds der Chemischen Industrie for a Dozentenstipendium.

\section{References and Notes}

1. Nyyssölä, A.; Kerovuo, J.; Kaukinen, P.; von Weymarn, N.; Reinikainen, T. Extreme Halophiles Synthesize Betaine from Glycine by Methylation. J. Biol. Chem. 2000, 275, 22196-22201.

2. Calas, M.; Cordina, G.; Bompart, J.; Bari, M.B.; Jei, T.; Ancelin, M.L.; Vial, H. Antimalarial Activity of Molecules Interfering with Plasmodium Falciparum Phospholipid Metabolism. Structure-Activity Relationship Analysis. J. Med. Chem. 1997, 40, 3557-3566. 
3. Katsh, S.; Keighley, G. Comparative Activities of Certain Quaternary Ammonium Compounds as Assayed by the Isolated Auricle Technique. Am. J. Physiol. 1953, 174, 431-435.

4. Brieskorn, C.H.; Herrig, H. Eigenschaften der Betainester einiger Sterine und pentacyclischer Triterpene. Fette Seifen Anstrichm. 1959, 61, 1077-1079.

5. Nockemann, P.; Thijs, B.; Pittois, S.; Thoen, J.; Glorieux, C.; Van Hecke, K.; Van Meervelt, L.; Kirchner, B.; Binnemans, K. Task-Specific Ionic Liquid for Solubilizing Metal Oxides. J. Phys. Chem. B 2006, 110, 20978-20992.

6. Wasserscheid, P.; Keim, W. Ionic liquids-new "solutions" for transition metal catalysis. Angew. Chem. Int. Ed. 2000, 112, 3772-3789.

7. Dean, P.M.; Turanjanin, J.; Yoshizawa-Fujita, M.; MacFarlane, D.R.; Scott, J.L. Exploring an Anti-Crystal Engineering Approach to the Preparation of Pharmaceutically Active Ionic Liquids. Cryst. Growth Des. 2009, 9, 1137-1145.

8. Stoimenovski, J.; MacFarlane, D.R.; Bica, K.; Rogers, R.D.; Crystalline vs. Ionic Liquid Salt Forms of Active Pharmaceutical Ingredients: A Position Paper. Pharmaceut. Res. 2010, 27, 521-526.

9. Zahn, S.; Wendler, K.; Delle Site, L.; Kirchner, B. Depolarization of water in protic ionic liquids. Phys. Chem. Chem. Phys. 2011, 13, 15083-15093.

10. Henschel, D.; Moers, O.; Wijaya, K.; Wirth, A.; Blaschette, A.; Jones, P.G. Schwache Wasserstoffbrücken mit aktivierten Methyldonoren: Kristallstrukturen von Cholinium-, Betainium- und Dimethyl[2-(dimethylamino)ethyl]ammonium-dimesylamid. Z. Naturforsch. 2002, $57 b, 534-546$.

11. Pearson, R.G. Hard and Soft Acids and Bases. J. Am. Chem. Soc. 1963, 85, 3533-3539.

12. Glowiak, T.; Durcanska, E.; Ondrejkovicova, I.; Ondrejovic, G. Structure of methyltriphenylphosphonium tetrachloroferrate(III). Acta Crystallogr. 1986, C42, 1331-1333.

13. Richards, R.R.; Gregory, N.W. The crystal structure of sodium tetrachloroferrate(III). J. Phys. Chem. 1965, 69, 239-244.

14. Meyer, G. Chlorometallate(III) mit Barytstruktur: CsFeCl4 und CsAlCl4. Z. Anorg. Allg. Chem. 1977, 436, 87-94.

15. Cerisier, J.; Guillot, C.; Palvadeau, P.; Rouxel, J. Characterization and study of physical properties and ionic conductivity of alkali metal tetrachloroferrates(1-) (alkali metal = lithium, sodium, potassium, rubidium, cesium). Eur. J. Solid State Inorg. Chem. 1988, 25, 35-52.

16. Baecker, T.; Breunig, O.; Valldor, M.; Merz, K.; Vasylyeva, V.; Mudring, A.-V. In-Situ Crystal Growth and Properties of the Magnetic Ionic Liquid [C2mim][FeCl4]. Cryst. Growth Des. 2011, $11,2564-2571$.

17. Baran, J.; Drozd, M.; Glowiak, T.; Sledz, M.; Ratajczak, H. Crystal structure, phase transitions and vibrational spectra of bis(betaine)nitrate. J. Mol. Struct. 1995, 372, 131-144.

18. Fischer, M.S.; Templeton, D.H.; Zalkin, A. Solid state structure and chemistry of the choline halides and their analogues. Redetermination of the betaine hydrochloride structure, $\left[\left(\mathrm{CH}_{3}\right)_{3} \mathrm{NCH}_{2} \mathrm{COOH}\right]^{+} \mathrm{Cl}^{-}$. Acta Crystallogr. 1970, B26, 1392-1397.

19. Steiner. T. The Hydrogen Bond in the Solid State. Angew. Chem. Int. Ed. 2002, 41, 48-76.

20. X-RED; Stoe \& Cie: Darmstadt, Germany, 2002. 
21. X-Shape; Stoe \& Cie: Darmstadt, Germany, 2002.

22. Sheldrick, W.S. SHELXS-97; Universität Göttingen, Göttingen, Germany, 1997.

23. International Table for Crystallography; Prince, E., Ed.; Kluwer Academic Publishers: Dordrecht, The Netherlands, 2004; Volume C.

24. Diamond Ver. 3.2; Crystal Impact GbR: Bonn, Germany, 2010.

(C) 2012 by the authors; licensee MDPI, Basel, Switzerland. This article is an open access article distributed under the terms and conditions of the Creative Commons Attribution license (http://creativecommons.org/licenses/by/3.0/). 